\title{
CONSTRUYENDO CONSENSO Y LEGITIMIDAD. LA PROYECCIÓN POLÍTICA DEL CATECISMO DE ESCOLÁSTICO ZEGADA EN TIEMPOS DE LA ‘CONFEDERACIÓN’ ARGENTINA (1853-1862)*
}

\author{
POR \\ FEDERICO MEDINA \\ Becario CONICET - CEPIHA - Facultad de Humanidades - Universidad \\ Nacional de Salta (Argentina)
}

\section{RESUMEN}

En 1855 Justo José de Urquiza -presidente de la 'Confederación' Argentina- resolvió reeditar con fondos públicos el catecismo Instrucciones Cristianas y recomendarlo para la formación de niños en las escuelas de primeras letras de la 'Confederación'. El autor del texto fue el clérigo jujeño Escolástico Zegada (1813-1871). En la reescritura, exaltaba la administración de Urquiza y convocaba de forma explícita a los lectores a apoyar al gobierno. Para ello, el clérigo utilizó modelos bíblicos del catolicismo romano. En consecuencia, el presente trabajo analiza, en primer lugar, los motivos por los cuales Urquiza y miembros de su gabinete resolvieron reeditar el catecismo. En segundo lugar, se estudia cómo el clérigo construía simbólicamente el liderazgo de Urquiza al frente del gobierno nacional. Así, se busca comprender las particularidades de las relaciones entre poder temporal y poder celestial en la Argentina hacia mediados del siglo XIX.

\section{PALABRAS CLAVES}

Justo J. de Urquiza; Confederación Argentina; Escolástico Zegada; catecismo religioso; legitimación de lo político.

* Este trabajo forma parte de los proyectos de investigación CIUNSa. $1893 / 2$ y 1893/3. Agradecemos las valiosas sugerencias de los evaluadores anónimos de la Revista. 


\section{BUILDING CONSENT AND LEGITIMACY. THE POLITIC PROJECTION OF ESCOLÁSTICO ZEGADA'S CATECHISM IN TIMES OF THE 'CONFEDERACIÓN' ARGENTINA (1853-1862)}

\section{ABSTRACT}

In 1855 Justo José de Urquiza -president of the Argentine 'Confederation'- resolved reissue wiyh public funds the catechism Christian Instructions and recommend to the formation of children in primary schools of the 'Confederation'. The author of the text was jujeño cleric Escolástico Zegada (1813-1871). In rewriting, praised the Urquiza's administration and explicitly summoned for readers to support the government. For this, the cleric used biblical models of Roman Catholicism. Thus, this paper examines, firstly, the reasons why Urquiza and his cabinet resolved reissue the catechism. Secondly, is studied how symbolically constructed cleric Urquiza's leadership ahead of the national government. So, it seeks to understand the particularities of the relationship between temporal and heavenly power in Argentina by midnineteenth century.

\section{KEY WORDS}

Justo J. Urquiza; Argentine Confederation; Escolástico Zegada; religious catechism; legitimation of the political.

$\begin{array}{ll}\text { Recibido/Received } & 31-08-2013 \\ \text { Aceptado/Accepted } & 27-05-2014\end{array}$

\section{INTRODUCCIÓN}

A lo largo de la historia han existido diversas formas de catecismos que tuvieron como objetivo la transmisión y persuasión de diversos contenidos. En palabras de Nicole Lemaitre, la Reforma protestante y el Concilio de Trento inauguraron "el tiempo del catecismo" constituyéndose en hitos relevantes para el impulso y la formulación de catecismos religiosos en el mundo occidental. Puntualmente, Trento esperaba que los clérigos instruyeran a los fieles en materia de fe para atraer a los "perdidos" y ganar nuevas almas en la obediencia al dogma. A esto se sumaba, como parte integral de la propuesta, la explicación del evangelio 
CONSTRUYENDO CONSENSO Y LEGITIMIDAD. LA PROYECCIÓN 375 POLÍTICA DEL CATECISMO DE ESCOLÁSTICO ZEGADA EN TIEMPOS DE LA CONFEDERACIÓN ARGENTINA (1853-1862)

de un modo "fácil y comprensible", emulando la forma en que lo hacían los reformadores. ${ }^{1}$

Pero, también se escribieron catecismos políticos con el propósito de sostener a las autoridades de gobierno. ${ }^{2}$ En el espacio latinoamericano, específicamente en México y Venezuela, los estudios previos pusieron de manifiesto la importancia de estos catecismos en la formación de los ciudadanos en el nuevo contexto iniciado con las revoluciones de Independencia. Muchos de ellos, al igual que algunos de los religiosos, se usaron para la enseñanza de los niños. ${ }^{3}$

Por su parte, varios de los catecismos monárquicos, sobre todo los formulados hacia fines del siglo XVIII y principios del siglo XIX, armonizaron elementos políticos, religiosos y cívicos. En el caso de los de la monarquía española estuvieron imbuidos de las ideas de la ilustración católica. En otros casos y para esta época, hubo libros dedicados a la enseñanza de las escuelas de primeras letras, que no tenían el calificativo de "catecismo", pero encerraban en sus páginas las mismas estrategias de escritura de los que sí se denominaban catecismos aunque con contenidos explícitamente políticos en los que se combinaron normas de civilidad y principios religiosos. Varios de estos tratados sirvieron de modelos en la elaboración del catecismo

${ }^{1}$ Lemaitre, N. 2002 (dir.). Histoire des curés, Paris: Fayard.

2 Sotés Elizalde, M. Á. 2009. "Catecismos políticos e instrucción política y moral de los ciudadanos (siglos XVIII y XIX) en Francia y España". Educación XXI. Nro. 12: 201-218. España: Universidad Nacional de Educación a Distancia.

3 Los catecismos políticos se generalizaron con la crisis de las monarquías europeas, los nuevos idearios de la Revolución Francesa y los gobiernos republicanos. Abogaban a favor de una u otra forma de ejercer del poder político, acompañando los cambios o las permanencias de las formas de gobierno. Ver: para Europa Sotés Elizalde, M. A. 2009: 201-218. Para América: Salcedo Baeza, R. 1996. "Actores políticos en los catecismos patriotas y republicanos americanos, 1810-1827". Historia Mexicana XLV. Nro. 3: 501538; Traffano, D. 2007. "Educación, civismo y catecismos políticos. Oaxaca, segunda mitad del siglo XIX". Revista Mexicana de Investigación Educativa. Vol. 12. Núm. 12: 1043-1063; Arredondo López, M. A. 2004. "Desplazando al rey en la escuela de la nueva nación mexicana: El "Catecismo de la República"”. Historia de la Educación. Núm. 22-24: 259-272. Ediciones Universidad de Salamanca y Robles, A. Cappello, H. y López Sánchez, J. 2007. "Características del proyecto educativo bolivariano: el tránsito del vasallo al ciudadano (1810-1830)". Revista Internacional de Ciencias Sociales y Humanidades. Año/vol. XVII. Núm. 001: 93-113. Universidad Autónoma de Tamaulipas. 
Instrucciones Cristianas ${ }^{4}$ del clérigo jujeño Escolástico Zegada (1813$1871)^{5}$, del que nos ocuparemos en este trabajo.

El catecismo de Zegada tuvo tres ediciones (1847, 1857 y 1869). En este artículo nos concentraremos en la segunda en tanto su reedición fue una decisión tomada por el presidente de la 'Confederación' Argentina $^{6}$ Justo José de Urquiza y por ambas cámaras del Congreso nacional, financiándose con fondos del erario público. ${ }^{7}$ El texto fue recomendado para la enseñanza primaria en las escuelas de ambos sexos de la Confederación. Esto se debió seguramente a que la versión original de 1847 contenía pautas de civilidad y urbanidad.

En la nueva edición de 1857, el autor incorporó nuevos capítulos agrupados bajo el subtítulo de Reflexiones religiosas y sociales dirigidas a los pueblos argentinos. Allí, impugnaba las prácticas políticas llevadas adelante por el gobernador de Buenos Aires Juan Manuel de Rosas. ${ }^{8}$

${ }^{4}$ Se pueden nombrar los textos de Juan de Escoiquiz Tratado de las obligaciones del hombre, de Juan Bautista Blanchard Escuela de Costumbres o Máximas razonadas de filosofía moral, para formar hombres de bien y buenos ciudadanos, del Abbate Sabatier El Amigo de los niños y de José de Urcullu Lecciones de moral, virtud y urbanidad. Estos libros nos permiten conjeturar las fuentes ideológicas sobre las que se basó Zegada para elaborar su catecismo, las mismas se referían a textos ilustrados españoles de la segunda mitad del siglo XVIII. Cf. Medina, F. 2012. "Entre la Ilustración española y las ideas contrarrevolucionarias francesas: el universo intelectual de la producción escrita de Escolástico Zegada (1813-1871)", en G. Caretta e I. Zacca (comps.) Derroteros en la construcción de Religiosidades. Sujetos, instituciones y poder en Sudamérica, siglos XVII al XX: 107-122. Salta: CEPIHA, UNSTA, CONICET.

${ }^{5}$ Escolástico Zegada nació en Jujuy, provincia argentina desde 1834. Allí vivió la mayor parte de su vida durante las décadas centrales del siglo XIX. Desde el punto de vista eclesiástico, el espacio de la provincia coincidía con el de la vicaría foránea que, en el tiempo de actuación de Zegada, dependía del Obispado de Salta (Argentina).

${ }^{6}$ Conviene señalar que la Constitución de 1853 sancionó un Estado federal. No obstante, utilizaremos el término Confederación en virtud de su generalizado uso en la literatura sobre el tema y en las fuentes documentales. En adelante el concepto se usará sin comillas.

${ }^{7}$ En esta época, es decir entre 1853 y 1862, coexistieron en el espacio rioplatense dos estados, el de la Confederación con sede en Paraná y el estado de Buenos Aires que, al retener para sí los fondos de su aduana, no integró la Confederación liderada por Urquiza.

8 En 1835 Juan Manuel de Rosas asumió por segunda vez la gobernación de la provincia de Buenos Aires. El resto de las provincias rioplatenses le cedieron el manejo de las Relaciones Internacionales. En el espacio rioplatense se construyó un orden republicano federal particular. En este línea, Marcela Ternavasio sostiene que se trató de "una federación que no era estrictamente un orden confederal ni un sistema federal de gobierno sino 
Por otro lado, exaltaba el liderazgo de Urquiza al frente del gobierno nacional así como a su administración. A la vez, convocaba explicita y contundentemente a los lectores a apoyar al gobierno. De esta manera, el catecismo religioso se convertía también en catecismo político. En consecuencia, Urquiza contó con un instrumento más que colaboraba, desde lo simbólico, en la legitimación del nuevo orden político inaugurado en 1853 y en la búsqueda de consenso hacia su gobierno.

Las representaciones construidas por Zegada en su catecismo y la buena recepción por parte de los miembros del poder central constituyen indicios que matizan las interpretaciones de Tulio Halperín Donghi en Proyecto y construcción de una nación (1846-1880), en el sentido que los proyectos de país propuestos hacia 1853 con una fuerte carga religiosa eran anacrónicos o superfluos. ${ }^{9}$ Zegada en las páginas de su catecismo, avalado y elogiado por las autoridades políticas y eclesiásticas de la Confederación, planteaba consolidar un orden republicano católico romano y asimilaba -siguiendo el relato bíblico- las acciones del líder político de la Confederación -Urquiza- a las acciones de Moisés y Jesucristo.

Estudiar las condiciones que hicieron posible la segunda edición del catecismo del cura nos permite observar -y aportar elementos para comprender- ciertos cambios del mundo político y del mundo eclesiástico operados hacia mediados del siglo XIX que implicaron la institucionalización del Estado y de la Iglesia en la Argentina.

A partir de 1853 se puede constatar la presencia de un nuevo orden político y la necesidad de hacerlo viable. La arenga a favor del

una compleja ingeniería política que presuponía un orden supraprovincial que reposaba sobre la provincia más poderosa, Buenos Aires, y más específicamente sobre su Primera Magistratura ejercida a través de un régimen unanimista y plebiscitario centrado en la figura de Juan Manuel de Rosas". Cf. Ternavasio, M. 2012. Historia de la Argentina, 1806-1852: 214-215. Buenos Aires: Siglo XXI. En la consolidación de ese orden federal peculiar se combinaron diversos elementos, desde el consenso hasta la coerción. Cabe aclarar que se pueden reconocer diferentes momentos en el ejercicio de estas prácticas. También es importante no perder de vista las especificidades del orden federal en las provincias. Rosas sería desplazado del poder en 1852 en la batalla de Caseros. La bibliografía sobre la temática es muy amplia, se pueden consultar las siguientes obras generales: Goldman, N. 2005 (dir.). Nueva Historia Argentina. Revolución, República, Confederación (1806-1852). Tomo III. Buenos Aires: Sudamericana; y Ternavasio, M. 2009.

${ }_{9}$ Estas referencias se deducen a partir de la exposición que realiza el autor de la propuesta de Félix Frías. Cf. Halperín Donghi, Tulio. 2007 (1997). Proyecto y construcción de una Nación (1846-1880): 43-47. Buenos Aires: Emecé editores. 
gobierno realizada por el autor del catecismo fue sin dudas un punto en esa dirección.

Además, no debe perderse de vista que él que gestionó la segunda edición e intervino en los nuevos agregados que se hicieron al texto original fue el ministro del gobierno nacional e intelectual de renombre, Juan María Gutiérrez. La reedición fue una instancia que le permitió a Zegada contactarse y vincularse con los hombres del poder central. Es preciso señalar aquí, basándonos en la más reciente producción historiográfica, que estas vinculaciones son otra muestra de la circulación de información y solidaridades así como de la edificación de redes de relaciones personales que fueron hilvanando el entramado políticoinstitucional de la Confederación. ${ }^{10}$ Según han aportado los estudios de referencia, estas conexiones entre los dirigentes nacionales y provinciales, constituyen un aspecto central en la construcción del Estado en formación. ${ }^{11}$ En ellos se ha remarcado la importancia que tuvo este período en los términos de aprendizaje y ensayo que luego será capitalizado en la presidencia de Bartolomé Mitre iniciada en 1862, ya con el país unificado. ${ }^{12}$

De forma paralela a la formación del Estado nacional se estaba construyendo la Iglesia nacional. En las páginas de su catecismo, Zegada, valoraba positivamente las medidas en materia religiosa de la Confederación, como muchos de los clérigos de la época. Conviene señalar, siguiendo los trabajos de los últimos años, que esas políticas fueron formuladas y ejecutadas por un Estado que, haciendo uso de su soberanía, participó en la reorganización eclesiástica iniciada por estos años, situación que no implicó necesariamente que el universo eclesiástico quedara sumido a la tutela del Estado. El propio ámbito eclesiástico se encontraba redefiniendo su arco de competencias, visibilizando una mayor homogeneidad interna y unidad de fines, en cuyo

10 Lanteri, A. L. 2013. "La 'Confederación' desde sus actores. La conformación de una dirigencia nacional en un nuevo orden político (18521862)", en A. L. Lanteri (coord.), Actores e identidades en la construcción del Estado nacional: 129-170. Buenos Aires: Teseo; Lanteri, A. L. 2008. "La justicia federal en la 'Confederación' Argentina (1854-1861). Apuntes sobre un intento de articulación entre Nación y provincias", Revistas Territórios e Fronteiras, Vol. 1. Núm. 1: 35-61. Mestrado em História do ICHS/UFMT y Lanteri, A. L. 2010. "La conformación de una dirigencia nacional. Notas sobre la dinámica política en el Congreso de Paraná (1854-1861)", en V. Ayrolo (comp.), Economía, Sociedad y Política en el Río de la Plata del Siglo XIX. Problemas y debates: 125-139. Rosario: Prohistoria.

${ }^{11}$ Bragoni, B. y Míguez, E. 2010. "Introducción: de la periferia al centro: la formación de un sistema político nacional, 1852-1880", en B. Bragoni y E. Míguez (coords.), Un nuevo orden político. Provincias y Estado Nacional 18521880. 9-28. Buenos Aires. Biblios.

${ }^{12}$ Lanteri, A. L. 2010: 125-139. 
CONSTRUYENDO CONSENSO Y LEGITIMIDAD. LA PROYECCIÓN 379 POLÍTICA DEL CATECISMO DE ESCOLÁSTICO ZEGADA EN TIEMPOS DE LA CONFEDERACIÓN ARGENTINA (1853-1862)

proceso se destacó el rol emprendido por la Santa Sede. La Constitución Nacional aprobada en 1853 -a la que nuestro personaje llamó a acatarsancionaba un presupuesto nacional de cultos, la libertad religiosa y el Estado se instituía como patrono nacional. ${ }^{13}$

En este marco, centrándonos en la historia de la segunda edición del catecismo, las páginas que siguen pretenden abordar las relaciones entre el gobierno nacional y los valores religiosos. Por ello es necesario atender a los siguientes interrogantes: ¿cómo el catecismo llegó a manos de Urquiza?, ¿por qué éste, y miembros de su elenco de gobierno, resolvieron editarlo?, ¿por qué Zegada puso en valor las medidas del gobierno de Urquiza, en especial las religiosas?, ¿por qué el cura terminó adhiriendo de forma explícita a este sector político? y ¿cómo interpretó la gestión de Urquiza y qué elementos bíblicos usó para ello?

Las fuentes para la elaboración de este artículo están constituidas principalmente por la segunda edición del catecismo. Las otras ediciones serán utilizadas en la medida que nos ayuden a comprender la proyección política y la significatividad que tuvo esta edición. ${ }^{14}$ Buscando alcanzar este objetivo, la información extraída del catecismo será confrontada y examinada con el contenido de informes y cartas enviadas y recibidas por Escolástico Zegada, así como con documentación asociada a los miembros del poder central y a algunas autoridades eclesiásticas de la Confederación.

\section{CLAVES PARA ENTENDER LA DECISIÓN TOMADA POR JUSTO JOSÉ DE URQUIZA}

\section{Poder nacional y poder local}

El catecismo denominado Instrucciones Cristianas llegó a manos del presidente Urquiza gracias a las gestiones realizadas por Juan María

${ }^{13}$ Martínez, I. 2013. Una Nación para la Iglesia argentina. Construcción del Estado y jurisdicciones eclesiásticas en el siglo XIX. Buenos Aires: Academia Nacional de la Historia.

${ }^{14}$ Primera edición: Zegada, Escolástico. 1847. Instrucciones Cristianas. Sucre: Imprenta de Becche y Cia., en Archivo del Museo Histórico del Norte (en adelante AMHN). Segunda edición: Zegada, Escolástico. 1857. Instrucciones Cristinas. Entre Ríos: Imprenta del Uruguay, en Biblioteca Nacional de la República Argentina (en adelante BNRA). Tercera edición: Zegada, Escolástico. 1869. Instrucciones Cristinas, Buenos Aires: Imprenta de Pablo Coni, en Archivo del Complejo Cultural San Francisco de Salta (en adelante ACCSFS). 
Gutiérrez, hombre de su elenco político ${ }^{15}$ y por el jujeño Manuel Padilla, personaje estrechamente vinculado al clérigo. ${ }^{16}$ La Convención Constituyente -como espacio de encuentro, selección, negociación e integración de las elites provinciales en el nuevo orden ${ }^{17}$ - fue el lugar donde ambos se conocieron. Gutiérrez representaba a la provincia de Entre Ríos y Padilla a la de Jujuy. ${ }^{18}$

El legislador jujeño, escribía a Zegada desde Paraná, en enero de 1854 que había hecho conocer a algunos "amigos patriotas" los emprendimientos que éste llevaba a cabo en Jujuy y agregaba: "el Dr. Gutiérrez (...) se ha interesado para que le pida un ejemplar de su obra sobre explicación de la doctrina cristiana que desea conocer y yo me empeño con Ud. para que (...) me mande un ejemplar". ${ }^{19}$ La primera edición del catecismo llegó a Gutiérrez en la segunda mitad del año $1854 .^{20}$

Merced al vínculo entablado por Padilla, Zegada trabó amistad y se relacionó con Juan María Gutiérrez, quien a su vez fue el que le hizo conocer el catecismo a Justo J. de Urquiza. A los pocos meses,

15 Juan María Gutiérrez, literato e intelectual, fue uno de los integrantes del Salón Literario de 1837. A través de sus escritos fustigó a Juan Manuel de Rosas durante la década de 1840, por lo que debió exiliarse. Durante el tiempo de la Confederación urquicista ocupó varios cargos políticos. Cf. Terán, J. sin año. "Don Juan María Gutiérrez", en Gutiérrez, Juan María; Críticas y Narraciones: XV-XXIV. Buenos Aires: Editorial Jackson.

${ }^{16}$ Manuel Padilla, miembro de la élite jujeña, era Abogado. Fue varias veces legislador en Jujuy y un activo colaborador en el interregno "unitario" de 1850-1851. Luego de Caseros ocupó cargos en la representación nacional y en la justicia local de Jujuy. Hacia mediados del siglo XIX, era un propietario rural de importancia. Cf. Paz, G. 2003. "El gobierno de los "conspicuos": familia y poder en Jujuy, 1853-1875", en H. Sábato y A. Lettieri (comps.), La vida política en la Argentina del siglo XIX. Armas, votos y voces: 223-241. Buenos Aires: FCE; y Sánchez de Bustamante, T. 1957. Biografías históricas de Jujuy, Tucumán: Universidad Nacional de Tucumán.

${ }^{17}$ Lanteri, A. L. 2010: 125-139.

18 Sábato, H. 2012. Historia de la Argentina, 1852-1890. Buenos Aires: Siglo XXI.

19 Carta de Manuel Padilla a Escolástico Zegada, Paraná, 27 de enero de 1854. Citada en: Vergara, M. Á. 1940. Zegada. Sacerdote y Patricio de Jujuy: 174. Jujuy: Edición especial del Gobierno de Jujuy. El subrayado es nuestro.

${ }^{20}$ Esta referencia se desprende de la carta que le enviara Manuel Padilla a Gutiérrez en junio de 1854, en la que decía que desde Córdoba le había mandado la "obra del cura de este pueblo". Carta de Manuel Padilla a Juan María Gutiérrez, Jujuy, 28 de junio de 1854. Transcripta en: Archivo epistolario del Doctor Juan María Gutiérrez. Tomo III: 39. Buenos Aires: Biblioteca del Congreso de la Nación. Buenos Aires, 1982. 
CONSTRUYENDO CONSENSO Y LEGITIMIDAD. LA PROYECCIÓN 381

POLÍTICA DEL CATECISMO DE ESCOLÁSTICO ZEGADA EN TIEMPOS

DE LA CONFEDERACIÓN ARGENTINA (1853-1862)

Gutiérrez, le terminó proponiendo la redición del catecismo, decisión tomada en conjunto con el propio presidente:

“(...) le mostré [a Urquiza] el ejemplar que poseo de la edición boliviana y le leí algunos párrafos (...) No contribuirá poco a este fin el sentimiento patrio, puesto que es un sacerdote argentino el que en aquellas páginas se dirige a la conciencia de sus compatriotas". ${ }^{21}$

Como se puede ver, la influencia ejercida por el dirigente del elenco gobernante fue determinante en lo que respecta a la reedición en tanto medió influencias y le hizo conocer la obra al presidente Urquiza. Gutiérrez remarcaba en su carta que convocarlo y habilitarlo a Zegada era un sentimiento patrio. Este sacerdote argentino era ante todo un cura y un político de provincia.

En un contexto en el que el poder central requería estrechar lazos $y$ articularse con los poderes locales ${ }^{22}$, no debe haber sido menor el hecho que Zegada haya sido un hombre de provincia con un importante capital relacional construido en su sociedad local. La trayectoria de vida del cura estaba hilvanada por experiencias y saberes, proporcionados por su participación en diferentes espacios de poder.

Por esos años se encontraba al frente de la Iglesia matriz y de la vicaría foránea de la provincia. Durante la década de 1840 y la de 1850 participó en la política provincial, siendo varias veces diputado de la Legislatura e integró la Sociedad de Beneficencia local, fundada en 1844 y presidida la más de las veces por él mismo. Estos aspectos no sólo fueron conocidos por Juan María Gutiérrez sino por otro de los ministros del ejecutivo nacional y familiar de Zegada, Facundo de Zuviría. ${ }^{23}$

En su calidad de vicario foráneo de la provincia, el cura expuso la situación de la Iglesia de Jujuy en ocasión del censo eclesiástico de 1854

${ }^{21}$ Carta de Juan María Gutiérrez a Escolástico Zegada. Transcripta en Vergara, M. Á. 1940: 174. El subrayado nos pertenece.

22 Bragoni, B. y Miguez, E. 2010: 9-28.

${ }^{23}$ Zuviría era tío político de Escolástico Zegada. Una hermana de Zuviría estaba casada con José Ignacio Gorriti, hermano de Ana María, madre del cura de Jujuy. Zuviría lo conocía a Zegada desde su infancia, Charcas fue el ámbito donde pudieron actualizar el vínculo que los unía, cuando el jujeño estudiaba para ser sacerdote y el político salteño estaba exiliado por el faccionalismo federal. Vergara, M. 1940. 
manifestando su beneplácito por la medida tomada por el gobierno. ${ }^{24} \mathrm{La}$ repuesta al censo, en la que Zegada expuso las actividades que desempeñaba en la provincia, se publicó y circuló en el periódico oficial El Nacional Argentino, lo que reafirma la conjetura sostenida que los miembros del emergente poder nacional conocían algunas de las actividades y funciones que Zegada tenía en Jujuy.

La reedición del catecismo podía servir para obtener el apoyo de Zegada en este sistema de reciprocidades que se tejía y a la par iba dándole cohesión política a la Confederación. ${ }^{25}$ Este fue un compromiso que, como veremos, se expresó a la postre con los nuevos agregados a la edición oficial del gobierno urquicista.

\section{Poder nacional y catolicismo romano}

Es posible pensar que otra de las claves que nos lleven a comprender la decisión tomada por el poder central haya sido la voluntad de los dirigentes de la Confederación de consensuar con aquel sector de la sociedad preocupado por el lugar de la religión católica en la ingeniería institucional del Estado en formación.

Es preciso recordar que la Constitución nacional de 1853 introdujo cambios fundamentales en lo que se refiere a las relaciones entre poder político y poder religioso. Sancionó un presupuesto nacional de cultos, aprobó la tolerancia religiosa y el Estado se erigió como patrono nacional. Así, el Estado haciendo uso de su soberanía y a partir de las facultades proporcionadas por el patronato nacional, empezó a gravitar cada vez más en la vida eclesiástica argentina, la más de las veces los poderes locales (civiles y eclesiásticos) debieron negociar cuando no resignar la autonomía con la que se habían manejado hasta entonces. Uno de los argumentos que sustentaba el rol asumido por el Estado era la asistencia material a las instituciones eclesiásticas. ${ }^{26}$

Las partidas destinadas al ramo del culto fueron importantes y crecieron con el correr de los años en el período de la Confederación. No obstante, bueno es decir que el presupuesto no cubrió todos los gastos del culto o todas las demandas peticionadas por las iglesias de la Confederación. De hecho, fueron comunes los reclamos por más presupuesto o por pagos acordados y no abonados.

${ }^{24}$ BNRA. Informe de vicario foráneo Escolástico Zegada de fecha 12 de febrero de 1856, publicado en el diario El nacional. Agradecemos la gentileza en el envío de este material al Dr. Ignacio Martínez.

${ }^{25}$ Lanteri, A. L. 2013: 129-170.
${ }^{26}$ Martínez, I. 2013: 355-526. 
En tanto, la declaración de la tolerancia de cultos implicó asumir que el catolicismo no se identificaba con la sociedad toda, sino con una parte de ella. Esta transformación no fue menor ya que redefinió las características de la comunidad política y sus autoridades al desvincular la soberanía de una profesión de fe específica, la católica romana. ${ }^{27}$

Los debates suscitados y las posiciones sostenidas en la Convención Constituyente muestran que fueron pocas las voces que se opusieron al proyecto oficial de la Constitución. Sin embargo, representaban a un sector de la sociedad que se negaba a aceptar la desvinculación de la religión católica del marco normativo del nuevo Estado.

Fuera de la Convención, incluso aquellos que deseaban ver fortalecido al gobierno de Urquiza, temían por la pérdida de consenso que la administración urquicista había logrado en las provincias. En tal sentido, ejemplo de lo que decimos fueron las cartas emitidas por presbíteros cercanos al círculo urquicista que planteaban la preocupación, así como la sospecha de algunos gobernadores de la Confederación que la Constitución no fuera aceptada por "herética". ${ }^{28}$

El clérigo jujeño, en las páginas de su catecismo proponía una instrucción integral basada en los preceptos del catolicismo romano. Por ello puede sugerirse que la edición del catecismo de Zegada fue pensada también para consensuar con este sector de la comunidad política.

La buena recepción que la obra de Zegada tuvo entre las autoridades eclesiásticas de la Confederación fue un indicio de que este objetivo fue alcanzado. Además del obispo electo de Salta José Eusebio Colombres $^{29}$, el polémico provisor de la Diócesis de Cuyo, Timoteo

${ }^{27}$ Martínez, I. 2013: 507.

${ }^{28}$ En el primer caso nos referimos a la carta del Presbítero José Manuel Figueroa al delegado eclesiástico de Entre Ríos, Miguel Vidal. El ejemplo del segundo caso es un informe del gobernador de Santiago del Estero al propio presidente Urquiza en el que le expresaba que había escuchado que el gobernador de Catamarca le proponía al de Tucumán no aceptar la Constitución. Cf. Martínez, I. 2013: 513.

${ }^{29}$ AMHN, catálogo I, documento 76. Circular redactada por José Eusebio Colombres, obispo electo y gobernador eclesiástico del Obispado de Salta, 1 ero de mayo de 1856. 
Maradona -quien tuvo variados conflictos con el gobierno central ${ }^{30}$ aplaudieron la obra del cura de Jujuy. ${ }^{31}$

Conocimientos técnicos y normas de civilidad

El impacto positivo del catecismo se debía además a que éste informaba e instruía acerca de nuevas técnicas como así también incluía reglas de civilidad. Ahora bien, según refiere el propio Gutiérrez a Zegada, él mismo le habría leído a Urquiza algunos párrafos de la versión del catecismo de 1847:

“(...) entre ellos los dirigidos a aconsejar mejores métodos para domar animales y sobre la conveniencia de plantar árboles y aplicarse a la agricultura. Quise que él mismo juzgase de los buenos frutos que promete en la masa del pueblo argentino la difusión de aquel libro". ${ }^{32}$

De acuerdo al ministro, la lectura y enseñanza del catecismo podían servir para fomentar la aplicación a la agricultura y transmitir métodos para domar animales. Es importante decir que estas referencias fueron dimensionadas y puestas en valor por el ministro, ya que en la obra de Zegada estas ideas se desarrollaron en el marco general de las admoniciones del quinto mandamiento no matarás que, como explicó su autor, prohibía todos los daños de palabras, acciones y pensamientos en contra del prójimo y de sí mismo.

El pasaje referido a la doma de animales imprudentemente se encontraba en el apartado De las cosas dañosas para la salud, en el que Zegada no dejaba de señalar la relevancia del ser cuidadoso con los animales, por tratarse de un oficio de necesidad para el circuito económico extractivo. ${ }^{33}$ Por su parte, el dedicarse al cultivo de plantas útiles se presentaba en el apartado De las cosas que conservan la salud, como un medio que iba desde la distracción a la obtención de alimentos, tanto desde lo doméstico como desde lo extensivo, este último aspecto se puede interpretar a partir de las referencias al suelo jujeño: "tantos campos y terrenos fértiles y hermosos para la labranza". ${ }^{34}$

30 Entre ellos sublevar a los clérigos mendocinos a no jurar la Constitución Nacional de 1853. Al respecto puede consultarse Martínez, I. 2013.

31 Carta de Timoteo Maradona a Escolástico Zegada, San Juan, 6 de noviembre de 1858. Transcripta en: AMHN. Zegada, E. 1869: 31.

${ }^{32}$ Carta de Juan María Gutiérrez a Escolástico Zegada. Transcripta en Vergara, M. Á. 1940: 174. El subrayado nos pertenece.

${ }^{33}$ Esta afirmación se desprende de la lectura general de las reglas del quinto mandamiento. AMHN. Zegada, E. 1847: 130.

${ }^{34}$ AMHN. Zegada, E. 1847: 131. 
Puede sugerirse que la dedicación a la agricultura y el fomento de mejores técnicas para la doma de animales, que resaltó Gutiérrez, se articularon con otras prescripciones de Zegada vinculadas al mundo del trabajo rural y a la armonía del orden social. En esta dirección el cura se dirigía a los patrones rurales exhortándolos a que tengan una actitud justa y catequística con sus jornaleros y sirvientes conchabados. A ellos había que enseñarles la doctrina cristiana y estimularlos a que no disipen sus salarios en diversiones como el juego o la embriaguez que no sólo afectaban la salud espiritual, ya que eran considerados pecados, sino también la social, al interrumpir el normal funcionamiento de la actividades económicas y sociales. ${ }^{35}$

De esta forma, Zegada, proponía una relación laboral sin conflictos, viabilizada desde la fraternidad social del catolicismo romano y la aceptación del lugar que cada persona tenía en el orden social. La enseñanza del catecismo era vista por Zegada como una de las principales herramientas para disciplinar a los peones. El propósito era que, a través de su lectura y enseñanza, los peones aprendieran la doctrina y fueran obedientes a la voluntad del patrón. Por su parte, exhortaba al patrón a tener una actitud paternal y catequística con sus trabajadores, ya que debían formarlos en la doctrina y dirigirlos por el camino de la honradez y el abandono de los vicios.

El interés por estos temas se corresponde en Zegada a su formación clerical y a su pertenencia a la élite propietaria de tierras de la provincia de Jujuy, compartiendo de este modo el espacio elitario y sus preocupaciones, con Urquiza y con varios de los diputados nacionales con los que tomó contacto.

En este sentido, los párrafos elegidos por Gutiérrez para leerle a Urquiza denotan la sagacidad de éste dado que como seguramente esperaba, encontraron buena predisposición en Urquiza debido a su perfil agrarista. Y esta, no fue la primera vez que el entrerriano financió con fondos del erario público obras que alentaban el fomento de las actividades económicas agrarias. Por los años de 1848 y 1849 , siendo gobernador de su provincia natal, reimprimió el libro Observaciones sobre agricultura del clérigo José Pérez Castellanos, escrito en las primeras décadas del siglo XIX, y el Plan de ensayo sobre agricultura de Marcelo Ignes. ${ }^{36}$ Así, Urquiza, capitalizaba la experiencia de la década

${ }^{35}$ AMHN. Zegada, E. 1847. El subrayado nos pertenece.

${ }^{36}$ Bosch, B. 1980. Urquiza y su tiempo: 125-137. Buenos Aires: Editorial universitaria de Buenos Aires. 
de 1840 vivenciada al frente del gobierno entrerriano y la proyectaba al espacio nacional.

Las propuestas vinculadas al mundo agrario, a la aplicación y dedicación al trabajo interpretadas y apropiadas por los hombres de la Confederación a partir de la lectura del catecismo, se inscribieron en un contexto en el que el país aceleraba el proceso de atlantización de su economía con la venta de productos primarios al mercado internacional. Conviene señalar que estas proposiciones cobraron, además, otra dimensión ya que, por el precario estado financiero de la Confederación al no contar con los recursos de la aduana de Buenos Aires que por ese momento se encontraba escindida de este sistema político, ${ }^{37}$ debía propiciarse el desarrollo económico autónomo pero inserto en el mercado internacional. Entonces la lectura de las ideas de Zegada, relacionadas a estos puntos y la transmisión del catecismo pensada desde el poder político, pueden comprenderse como parte del constante intento de los hombres del elenco nacional para revertir la situación económica.

La formación de personas laboriosas se concatenaba a otras preocupaciones desarrolladas por Zegada en sus escritos, que entendemos también interesaron a los hombres de la Confederación. Esto se tradujo en la expresión de Gutiérrez de que el catecismo del clérigo jujeño iba a "formar la conciencia de los compatriotas". A su vez, esta inquietud se vio reforzada por el decreto emitido por el propio Urquiza -refrendado por ambas cámaras del Congreso nacional- en el que afirmó que publicaba el catecismo del jujeño a fin de "generalizar en la masa del pueblo Argentino, las ideas de moral cristiana y el conocimiento de los deberes sociales, santificados por la doctrina del Evangelio". ${ }^{38}$

Los objetivos del poder central de instruir a la "masa" del pueblo argentino estuvieron presentes en la elección del catecismo. En este sentido, Zegada, pensaba la instrucción de los valores del catolicismo romano a todos los miembros de la sociedad, aunque insistió con recurrencia en el sector social que denominó vulgo. Zegada abogaba por inculcar y reforzar las normas de la convivencia social armoniosa, la fraternidad, el respeto y la amabilidad en el trato hacia las otras personas, el control por la conducta en la sociedad, el aseo personal y el control de las pasiones. ${ }^{39}$ Es decir, las normas de la urbanidad y la cortesía. La edificación de estas virtudes, venía de la mano de la formación de ciudadanos "útiles" y laboriosos. Exhortaba

${ }^{37}$ Sábato, H. 2012.

38 Decreto emitido por Justo José de Urquiza, Paraná, 27 de julio de 1855. Transcripto en: ACCSFS. Zegada, E. 1869: 29.

${ }^{39}$ AMHN. Zegada, E. 1847. 
CONSTRUYENDO CONSENSO Y LEGITIMIDAD. LA PROYECCIÓN 387 POLÍTICA DEL CATECISMO DE ESCOLÁSTICO ZEGADA EN TIEMPOS DE LA CONFEDERACIÓN ARGENTINA (1853-1862)

incansablemente a erradicar la ociosidad. ${ }^{40}$ Así, el autor ya proponía en la primera edición afianzar las formas de coacción social y el auto control de las conductas de las personas en pos de favorecer a una mayor utilidad de las mismas y apostar a una mejor convivencia en la sociedad. ${ }^{41}$

En la nueva edición financiada por Urquiza, retomando este hilo conductor, insistirá en asociar las virtudes "del mundo civilizado" moderno -que se pueden agrupar en el concepto de civilidad- con las virtudes del evangelio. Así, nombraba al "patriotismo, honor civil, generosidad, honradez, hombría de bien, finura en el trato, atención, política [cortesía], urbanidad". ${ }^{42}$ Era firme en su posición de exaltar las virtudes consideradas importantes en el mundo moderno en la medida en que se amalgamaran a la doctrina cristiana. Recuperaba así la noción cristianizada del concepto de civilidad, aspecto que como se sabe fue un eslabón más en la trayectoria semántica de la mismo. ${ }^{43}$

Todos estaban llamados a la lectura y a la enseñanza del catecismo. Gran parte de esa población -el vulgo- que el autor se proponía instruir era analfabeta. Por ello, en el Prólogo de las sucesivas ediciones, invitaba particularmente a los párrocos y padres de familia a que difundieran los contenidos del catecismo. La invitación formulada en sus páginas, se reforzó con una circular del obispo de Salta José Eusebio Colombres de 1856 en la que recomendaba a los curas párrocos del obispado la enseñanza del catecismo de Zegada. ${ }^{44}$

\section{LEGITIMACIÓN DEL GOBIERNO DE JUSTO JOSÉ DE URQUIZA}

\section{Conjeturas sobre la posición asumida por Zegada}

La publicación del catecismo de Escolástico Zegada fue una propuesta de Juan María Gutiérrez que contó con el acuerdo del presidente Urquiza. Ante tal honor Zegada agradecía y cedía su libro a los miembros del poder central expresándole que consideraran al

${ }^{40}$ AMHN. Zegada, E. 1847: 88 y 89.

41 Características que se pueden englobar en el concepto de proceso civilizatorio propuesto por Elías. Cf. Elias, N. 2009 [1986]. Proceso de la civilización, México: FCE.

42 BNRA. Zegada, E. 1857: 378.

${ }^{43}$ Chartier, R. 1993. "Manuales de civilidad. Distinción y divulgación: la civilidad y sus libros", en Libros, lecturas y lectores en la Edad Moderna: 246283. Madrid: Alianza.

${ }^{44}$ AMHN, catálogo I, documento 76. Circular redactada por José Eusebio Colombres, obispo electo y gobernador eclesiástico del Obispado de Salta, 1ero de mayo de 1856. 
catecismo como una propiedad del gobierno. Además se comprometió a revisar el texto y realizar los cambios que sugería Gutiérrez. ${ }^{45}$

La reedición del catecismo fue vista por el elenco urquicista como una contribución al programa del gobierno. La nueva edición se convirtió así en un instrumento que permitía generar consenso con los poderes locales, sea con dirigentes locales provinciales -Zegada era uno de elloscomo con aquel sector de la sociedad preocupado por el lugar de la religión en la nueva ingeniería institucional que estaba adoptando el Estado en ciernes. Por otro lado, el relato del catecismo podía ser aprovechado para trasmitir a los compatriotas conocimientos técnicos vinculados a la economía rural y normas de civilidad que tendieran a disciplinar la sociedad. Sus ventajas eran variadas y múltiples.

Desde 1840, Zegada insistía en superar los conflictos políticos y sociales provocados por las disputas políticas, en particular las de unitarios y federales. El deseo que cicatrizaran estas heridas posiblemente explique que haya visto en Urquiza un dirigente que encarnara dicha posibilidad en contraposición a Rosas de quien tenía el peor de los conceptos.

El cura se sintió motivado por el discurso de Urquiza quien al inaugurar el Congreso Constituyente de Santa Fe decía: "la intolerancia, la persecución, el exterminio fueron la base de su política [en alusión a Rosas]; y yo adopté por divisa de la mía, el olvido de todo lo pasado y la fusión de partidos". ${ }^{46}$ Urquiza intentó llevar estas ideas a la práctica y siguiendo la pauta de su gestión provisoria, conformó -por ejemplo- un gabinete con personalidades de cierto prestigio provenientes de distintas provincias, de disimiles filiaciones políticas e ideológicas, aunque comprometidas con la gestión de gobierno. ${ }^{47}$ Así, en las representaciones de Zegada, el proyecto de Urquiza simbolizaba la unidad nacional que por lo demás se materializaba en la Constitución Nacional.

Además, Zegada, aplaudió las medidas en materia religiosa llevadas a cabo por el emergente gobierno nacional. Estas políticas respondieron al estado de las iglesias locales en los años cincuenta del siglo XIX. Luego de la Revolución fueron comunes los conflictos de poder

${ }^{45}$ Carta de Escolástico Zegada a Juan María Gutiérrez, Jujuy, 21 de junio de 1855. Transcripta en: Archivo epistolario del Doctor Juan María Gutiérrez. Tomo III: 291-292. Buenos Aires: Biblioteca del Congreso de la Nación. Buenos Aires, 1982. El resaltado y el subrayado nos pertenece.

46 Citado en: Romero, J. L. 2008. "El pensamiento conciliador y la organización nacional", en Las ideas Políticas en la Argentina: 133-169. Buenos Aires: FCE.

${ }^{47}$ Sábato, H. 2012: 17-65. 
entre autoridades civiles y eclesiásticas a causa del manejo de las atribuciones del Patronato y frecuentes los testimonios de escasez del clero y la falta de idoneidad de los pocos efectivos que ejercían el ministerio. ${ }^{48}$

Con el ocaso del rosismo en 1852 se inició un proceso de recuperación eclesiástica y de reconstrucción de las estructuras diocesanas que no se completará sino a finales del siglo XIX principios del XX. ${ }^{49}$ Interesa remarcar y tener en cuenta que, promediando la mitad de la centuria decimonónica, la Iglesia nacional, desde una óptica institucionalizada, se encontraba en dinámica de edificación en forma paralela al Estado. ${ }^{50}$

El gobierno nacional demostró su interés por la organización de las diócesis y su regularización, interés compartido por Zegada, en el momento de la organización del censo de 1854. El conocimiento del

48 La bibliografía al respecto es mucha. Puede consultarse la obra general: Di Stefano, R. y Zanatta, L. 2009. Historia de la Iglesia Argentina: 299303. Buenos Aires: Sudamericana.

49 Di Stefano, R. y Zanatta, L. 2009: 303.

50 Sin embargo, la discusión no se encuentra cerrada en torno a qué actor tuvo mayor importancia en la edificación de la Iglesia nacional. Se puso de relieve que la mencionada construcción fue una cuestión de Estado en tanto soberano y que actores como la Santa Sede ocuparon un rol de reparto. Cf. Lida, M. 2006 a. "Una Iglesia a la medida del Estado: la formación de la Iglesia nacional en la Argentina (1853-1865)", Prohistoria. Año X. Núm. 10: 27-46. Rosario. Se ha enfatizado en la contribución de la feligresía que empezaría a hacer de su fe una causa militante, Cf. Lida, M. 2006 b. "Prensa católica sociedad en la construcción de la Iglesia argentina en la segunda mitad del siglo XIX": 51-75, en: Anuario de Estudios Americanos, 63, 1, enero-junio; y Abalo, E. 2012. "Construir la Iglesia: clero, feligresía y Estado provincial ante la edificación de templos en la vicaría foránea de Tucumán (1852-1897)": 5-26, en: Bicentenario. Revista de Historia de Chile y América, Vol. 11, Nro. 2. Santiago de Chile. Finalmente, se ha recogido estos aportes y se ha estudiado la edificación desde el punto de vista de las disposiciones legales y de las prácticas de los agentes estatales y eclesiásticos que coadyuvaron a ese fin. Se incorporó al análisis, a diferencia de lo planteado por Lida, la participación que en dicho proceso tuvo la Santa Sede, pues se ha sostenido que era una de las partes ineludibles en el ejercicio del Patronato. Cf. Martínez, I. 2013. Por otro lado se insistió en que la Santa Sede iniciaría un período de unificación a escala global, destacándose dentro del proceso el rol del pontificado de Pio IX (1846-1878) y la creación del Vaticano en 1871. Cf. Ayrolo, V. 2009. "La travesía de la "Iglesia" del Río de la Plata, Tucumán y Cuyo entre la Colonia y la Nación": 25-52, en: A Agreja Católica Em Mato Grosso E Os Cem Anos Da Arquidiocese De Cuiabá (1910-2010). Cuiaba-Brasil: Ed. UFMT Editora de la Universidad Federal de Mato Grosso. 
estado eclesiástico del nuevo país permitiría racionalizar el área del culto en el presupuesto nacional. En este proceso el ministerio de Culto, Justicia e Instrucción Pública ocupó un rol central dado que esta cartera era la que determinaba a quién se pagaba, cuánto y en qué condiciones. ${ }^{51}$ Así, se refaccionaron y construyeron templos, se dispuso una escala de sueldos para los prebendados y el gobierno se comprometió a aportar fondos para la erección de seminarios, condición que había impuesto la Santa Sede para autorizar la inauguración ${ }^{52}$.

Un dato que no es menor fue que durante este período se buscó regularizar la designación de las autoridades eclesiásticas. En este sentido, Escolástico Zegada era uno de los hombres que tenía posibilidades de ser propuesto como obispo. Así lo deja ver el informe escrito del ministro Facundo de Zuviría al Nuncio del Papa, Marino Marini. ${ }^{53}$ La expectativa por alguna silla diocesana de la Confederación nos dimensiona también la posición asumida por Zegada respecto al gobierno junto con su beneplácito por la política religiosa que por entonces la dirigencia nacional emprendía.

\section{Urquiza}

Lecturas bíblicas y construcción de la heroicidad de Justo José de

Los estudios historiográficos de los últimos años han llamado la atención acerca de la importancia que tiene el abordaje de los usos y lecturas que tuvo la Biblia para interpretar hechos políticos y sociales. En lo que respecta al siglo XIX latinoamericano, pasajes y analogías de la Biblia fueron utilizados en diferentes períodos, otorgando inteligibilidad y legitimidad a los procesos de rupturas y a la edificación de nuevos órdenes políticos, particularmente. Así, las sucesivas fases de las revoluciones de Independencia fueron momentos privilegiados para su uso. ${ }^{54}$ Para el período que nos ocupa y en el marco del censo

${ }^{51}$ Martínez, I. 2013.

52 Lida, M. 2007. "El presupuesto de culto en la Argentina y sus debates. Estado y saciedad ante el proceso de construcción de la Iglesia (1853-1880)", Revista Andes. Antropología e Historia, Núm. 17: 49-76. CEPIHA-UNSa.

${ }^{53}$ Una información del Doctor Facundo Zuviría sobre eclesiásticos al Nuncio del Papa Marino Marini, Montevideo 6 de abril de 1856. Agradecemos a la Dra. Ana Laura Lanteri el habernos facilitado gentilmente esta fuente documental.

${ }^{54}$ A modo de ejemplo, para el caso del Río de la Plata pueden consultarse los trabajos de Di Stefano, R. 2003. "Lecturas políticas de la Biblia en la revolución rioplatense (1810-1833)", Anuario de la Iglesia. Núm. XII: 201224. Universidad de Navarra; y Peire, J. 2000. El taller de los espejos. Iglesia e imaginario 1767-1815. Buenos Aires: Editorial Claridad. Con el seudónimo de José Amor a la Patria en 1810 se publicó en Chile un Catecismo político cristiano, que se atribuye a Bernardo de Vera y Pintado. Este catecismo estuvo dirigido, según Donoso que fue quien lo publicó, a todos los americanos. 
CONSTRUYENDO CONSENSO Y LEGITIMIDAD. LA PROYECCIÓN 391

POLÍTICA DEL CATECISMO DE ESCOLÁSTICO ZEGADA EN TIEMPOS

DE LA CONFEDERACIÓN ARGENTINA (1853-1862)

eclesiástico de 1854 llevado a cabo por el gobierno urquicista, a través de su ministro Facundo de Zuviría, el personal eclesiástico a cargo de las jurisdicciones religiosas tendió a considerar, en su mayoría, las políticas en materia eclesiástica como parte de la Historia Sagrada. ${ }^{55}$ Es allí donde se puede contextualizar el relato de Escolástico Zegada.

Como se adelantó, las valoraciones referidas al gobierno nacional de Urquiza y a su persona se incorporaron a la edición del catecismo de 1857 en el apartado denominado Reflexiones religiosas y sociales dirigidas a los pueblos argentinos. A diferencia de varios de los clérigos a cargo de jurisdicciones de la Confederación, el cura de Jujuy tuvo la oportunidad de ampliar sus ideas y articularlas en un andamiaje más vasto de sentido. Estas construcciones simbólicas se formularon en y fueron parte de un catecismo religioso, lo que le otorga a su relato otra dimensión. Según las propias palabras del clérigo Las Reflexiones continuaban las anteriores lecciones del catecismo ${ }^{56}$, libro que en sus primeras páginas decía:

"Os presento este libro que contiene las verdades que, el Dios de las misericordias ha enseñado a los hombres (...) para manifestarnos o recordarnos los beneficios que nos ha hecho: para asegurarnos los que todavía nos ofrece: para enseñarnos nuestras obligaciones y el fin para que nos ha criado". ${ }^{57}$

En este mismo tono, las alusiones a Urquiza y a su gobierno integraban esas verdades que Dios había enseñado, aseguraba y ofrecía. Con ello el catecismo religioso pasaba a participar en la

Donoso, R. 1943. "Estudio preliminar", en Revista de Historia y Geografía Chilena: 12-119. Para México los de Connaughton, B. 1995. "La sacralización de lo cívico: la imagen religiosa en el discurso cívico-patriótico del México independiente. Puebla (1827-1853)": en: Matute, Á., Trejo, E. y Connaughton, B. (coords.) Estado, iglesia y sociedad en México. Siglo XIX: 223-250México: UNAM.; y Cañizares Esguerra, J. 2013. "Son las Mujeres las que Defienden al Rey con Espadas y son los Liberales los que Queman Herejes: El Antiguo Testamento y las Revoluciones de Independencia en la Monarquía de España”, en: 20/10, El Mundo Atlántico e Iberoamérica, 1750-1850, Nro. 2, México. En línea: http://www.20-10historia.com/emaylmi-v2-articulo1.phtml (consulta el 11 de mayo de 2014).

55 Abalo, E. 2009 a y b; y 2012. Los informes de las iglesias locales fueron trabajados también por: Auza, N. T. 1979. "La política religiosa de la Confederación. El censo religioso de 1854", en Revista Histórica,3. Buenos Aires.

\footnotetext{
${ }^{56}$ BNRA. Zegada, E. 1857: 366.

${ }^{57}$ BNRA. Zegada, E. 1857: IX.
} 
construcción de lo político, ${ }^{58}$ legitimando el nuevo orden inaugurado en 1853. Esta legitimación estuvo anudada a interpretaciones bíblicas que pusieron a Rosas del lado del déspota y a Urquiza del libertador. Zegada explicaba el liderazgo de Urquiza al frente de la Confederación a partir de las diferencias que avizoraba entre el gobierno del entrerriano y el régimen rosista caído en 1852 . Así, se refería:

"Acordémonos también de que el Señor de los Ejércitos tiene en sus manos la suerte de las naciones: las exalta o abate con un acto de su voluntad. En su justo enojo las deja oprimir por déspotas, y en su misericordia suscita héroes que las liberen. Al presente no podemos desconocer este beneficio que nos ha dispensado cuando menos lo merecíamos". ${ }^{5}$

Como vemos, Zegada daba cuenta del liderazgo de Rosas y de Urquiza como actos de la voluntad divina en tanto componentes de la Historia de la Salvación de la tradición judeocristiana. Así, argumentó que Dios mandaba déspotas para castigar a las naciones como escarmiento de sus pecados, al tiempo sostuvo que por su misericordia enviaba héroes para que las libertaran. Se puede sugerir que asociaba -en términos del relato bíblico- al tiempo de la opresión que sufrieron los israelitas en tierras del faraón egipcio con la época del régimen rosista en el Río de la Plata. En tanto, la liberación vivida por el Pueblo de Israel de la esclavitud egipcia la asimilaba a la época que se iniciaba en $1853 .{ }^{60}$

En el relato escatológico, la figura de Moisés cobra una dimensión central. Moisés es el elegido y enviado de Dios para liberar a su Pueblo (Éxodo 3,10). Era con Moisés que Zegada comparaba y asimilaba a Justo J. de Urquiza. En esta analogía, envuelta en el halo de la providencia divina, construía la heroicidad de Urquiza. La referencia fue explícita en la Manifestación dedicada a Urquiza al iniciarse la tercera edición del catecismo de 1869. Así se expresaba: "Vos, inspirado como otro Moisés, derribasteis ese nefando ídolo". ${ }^{61}$ El nefando ídolo era sin dudas Juan Manuel de Rosas. Precisamente, a partir de las críticas al rosismo, Zegada pudo formular un conjunto de ideas para validar el accionar de Urquiza y su gobierno.

${ }^{58}$ Pierre Rosanvallon afirma: "Referirse a lo político y no a la política es hablar de (...) todo aquello que constituye la polis más allá del campo inmediato por el ejercicio del poder, de la acción gubernamental del día al día y de la vida ordinaria de las instituciones". Cf. Rosanvallon, P. 2002. Por una historia conceptual de lo político: 19-29. Buenos Aires: FCE.

${ }^{59}$ BNRA. Zegada, E. 1857: 371.

60 Di Stefano, R. 2003: 201-224.

${ }^{61}$ ACCSFS. Zegada, E. 1869: XV-XVI. 
En las percepciones del cura, las prácticas políticas del rosismo habían enlutado a la República Argentina, fueron años caracterizados por el "caos, el despotismo y la tiranía". ${ }^{62}$ Para Zegada, la Patria, entendida como cuerpo social, estaba enferma y al borde de la muerte y fue Urquiza, con la ayuda divina, el que salvó a la Patria de su último respiro y la liberó de la tiranía rosista, propiciándole con el nuevo gobierno el remedio. ${ }^{63}$

En su visión, el remedio -a diferencia de la época rosista- era la puesta en práctica de un programa de gobierno evangélico. Para argumentar su posición retomó las ideas del entrerriano pronunciadas en el contexto de la Convención Constituyente de 1853: "jolvidos de agravios! jfusión de partidos!" ${ }^{64}$ Para el cura esta posición significaba la superación de los conflictos que habían dividido a la sociedad en el pasado y la apelación a un objetivo de gobierno que se ocupara de las necesidades de la religión y la Iglesia. ${ }^{65}$

Merece destacase en este último sentido, por los cambios que por la hora se gestaban en el mundo eclesiástico, que la postura asumida por Zegada se identificaba a la perspectiva de varios clérigos de la Confederación -como Manuel Antonio Castellanos, Vicario Capitular de Salta- e intelectuales laicos de pública adhesión al catolicismo -como Félix Frías- que sostenía que el Estado debía proteger a la Iglesia pero al mismo tiempo respetar su autonomía jurisdiccional, en otras palabras, no "abusar" del Patronato. ${ }^{66}$ Además, como parte de este andamiaje de ideas por las que se perfila la constitución de una Iglesia nacional institucionalizada, el cura, se mostró siempre partidario de tener un

62 BNRA. Zegada, E. 1857: 387-397. Precisamente, en la sección "Sobre la usurpación y abuso del poder" se dedicó a señalar los aspectos que habían enfermado a la Patria y que caracterizaron los tiempos de la "anarquía" y la "tiranía". Se trataba de la experiencia de la república enlutada. En la tercera edición aclaró que ese capítulo había sido "escrito en la época de Rosas [...] todo lo que se dice y mucho más ha sucedido en ellas". ACCSFS. Zegada, E. 1869: 378. En términos generales, denunciaba el abuso del poder de los gobernadores federales, lo que -siguiendo al autor- ocasionaba la pérfida de independencia de los poderes de gobierno. Sus mayores críticas estuvieron enfatizadas en el carácter despótico y tiránico de los gobiernos federales, ya que buscaron que "todo cuanto hay en la tierra se les someta" y "dominar y disponer a su arbitrio en todo". BNRA. Zegada, E. 1857: 366-461.

63 El autor del catecismo se refería a que la época actual (gobierno de Urquiza) era el remedio de los males del pasado. BNRA. Zegada, E. 1857: 401.

${ }^{64}$ BNRA. Zegada, E. 1857: 401.

65 Ídem.

66 Martínez, I. 2013: 498 y 499. 
contacto fluido con la Santa Sede. ${ }^{67}$ Es más, resaltará en 1869 que uno de los rasgos positivos de la labor de Urquiza había sido haber intentado entablar comunicaciones con Roma. ${ }^{68}$

Zegada, al calificar de evangélico al programa de gobierno, volvía a dotar de significado religioso al régimen. Los esquemas de pensamiento de Zegada remitían ahora al Nuevo Testamento que en clave bíblica significa buena noticia. La buena noticia era la salvación eterna de los hombres por la fe en Jesucristo. Cobran importancia en el mensaje evangélico las actitudes del perdón, del amor hacia los demás, la fraternidad, etc., encarnadas por Jesucristo, el Salvador y Señor de la Historia. Estas actitudes, Zegada, las veía en los dirigentes del poder central. De allí que postuló que la enlutada República se encontraba en tránsito del duelo al regocijo. ${ }^{69}$

Por ello, no se privaba de señalar los aspectos que estaban permitiendo ese pasaje y a la vez articulando el programa evangélico de gobierno:

"El plan de nuestras operaciones (...) lo vemos demarcado en la marcha administrativa del héroe que nos ha deparado la divina Providencia. Después que derribó el coloso de la tiranía, vemos su tendencia a dar al país leyes, humanidad, moralidad, religiosidad, educación, clero, etc." ${ }^{70}$

"Vemos iniciada la educación e instrucción nacional, y la atención a la religión y a la iglesia". ${ }^{71}$

El autor indicaba los pasos que el gobierno daba por entonces en relación al diseño de su ingeniería institucional, sus órganos administrativos y en torno a la consolidación de sus esferas de poder. Estas referencias le permitieron al clérigo jujeño no sólo legitimar en clave religiosa la "marcha administrativa del héroe" sino también realizar

${ }^{67}$ Al respecto puede consultarse la carta de Escolástico Zegada al Papa Pío IX, 29 de diciembre de 1847. Transcripta en: Archivum XX: 271- 280. Buenos Aires: Junta de Historia Eclesiástica Argentina, 2001.

68 ACCSFS. Zegada, E. 1869: XV-XVI. Sobre los intentos de entablar un concordato entre el gobierno argentino y la Santa Sede y en relación a la presencia insoslayable de este último actor, ver: Martínez, I. 2010. "Coincidencias sin acuerdo. Los primeros contactos entre el gobierno argentino y la Santa Sede en el proceso de construcción de la Iglesia nacional (18511860)", Nuevo Mundo Mundos Nuevos, Debates, puesto en línea el 11 de marzo de 2010: http://nuevomundo.revues.org/59082.

${ }^{69}$ BNRA. Zegada, E. 1857: 401.

${ }^{70}$ BNRA. Zegada, E. 1857: 401. El subrayado es nuestro.

${ }^{71}$ BNRA. Zegada, E. 1857: 370. 
CONSTRUYENDO CONSENSO Y LEGITIMIDAD. LA PROYECCIÓN 395

POLÍTICA DEL CATECISMO DE ESCOLÁSTICO ZEGADA EN TIEMPOS

DE LA CONFEDERACIÓN ARGENTINA (1853-1862)

una convocatoria a sus lectores, incluidos a quienes iban a transmitir los contenidos del mismo.

Vemos como convocaba a todos sus lectores a apoyar al gobierno del héroe que, en sus esquemas de percepciones, estaba "reanimando" a la República y otorgándole ser social y religioso ${ }^{72}$. Todos estaban convocados a acompañar este proceso. Zegada apreciaba una tendencia general, un cambio de época, cuyos frutos no debían ser contrariaros. Todo aquel que se opusiera era un ingrato, un perverso y atentaba en contra de los intereses de la Patria católica refundada por Urquiza en Caseros.

En este punto, es posible sugerir que la propuesta de Zegada volvía a encontrar su fuente de interpretación en el Antiguo Testamento y en la Alianza sellada entre Dios, Moisés y los israelitas. El Señor de los Ejércitos había ayudado a los israelitas para despojarse de la "tiranía" del faraón. En consecuencia, los israelitas tuvieron la obligación de establecer el culto de Dios y consagrarse a Él (Éxodo 19,6). Para Zegada, también se había establecido un Pacto, pues la Divina Providencia había enviado a Urquiza para terminar con la "tiranía" y el "despotismo" de Rosas, ahora había que acompañar, en la visión del cura, el orden republicano católico liderado por el vencedor de Caseros. De allí que pronunciara la siguiente expresión: "Al presente no podemos desconocer este beneficio que nos ha dispensado cuando menos lo merecíamos: nuestra conducta será la que lo haga verdadero o transitorio". ${ }^{73}$ Había que respetar el Pacto, para evitar el error que cometieron los israelitas. ${ }^{74}$ Por ello, apoyar al gobierno era un deber religioso.

En fin, fue central para los hombres de gobierno fomentar una educación que estuviera en sintonía con el nuevo orden político y su organización social y jurídica. ${ }^{75}$ De allí la relevancia de la proyección político-social del catecismo de Zegada y su consiguiente publicación.

\section{CONCLUSIONES}

La primera edición del libro se realizó en el año 1847. En este compendio se encontraron algunas claves que explican la decisión del poder central urquicista en financiar una nueva publicación en 1857 con algunos agregados. El discurso elaborado por Zegada, resultaba útil y

\footnotetext{
72 BNRA. Zegada, E. 1857: 409.

73 BNRA. Zegada, E. 1857: 371.

${ }^{74}$ Di Stefano, D. 2003: 201-224.

${ }^{75}$ Lanteri, A. L. 2008: 52.
} 
atractivo a los propósitos de la Confederación. Recordemos que en él llamaba la atención acerca de la formación de ciudadanos útiles al país y al disciplinamiento social. Particularmente bregó por superar la ociosidad y por inculcar patrones de laboriosidad en el vulgo. Insistió en promocionar ideas que tendían al establecimiento de relaciones laborales sin conflictos, basadas en la fraternidad cristiana. Es más, sugería la obediencia de los jornaleros y peones a sus patrones mientras que a estos los estimulaba a adoptar una postura paternal y catequística.

En el catecismo estos aspectos integraban prescripciones generales relacionadas a los mandamientos. Fue Juan María Gutiérrez el que las puntualizó y las puso en valor, potenciándolas en un contexto de atlantización de la economía y en momentos en el que Confederación necesitaba ampliar sus bases financieras al no contar con los recursos de la aduana de Buenos Aires.

La propuesta de reedición también debe ser comprendida en la trama de solidaridades -subrayada por los estudios recientes- en el cual el poder central buscaba tender lazos y consenso en las provincias. EI cura era un hombre de provincia con un gran capital relacional consolidado en su sociedad natal, su compromiso con el gobierno nacional se visualizó en los agregados de su catecismo.

Es posible conjeturar que la edición del catecismo pudo ser un medio para consensuar con el sector de la sociedad rioplatense preocupado por el lugar de la religión católica en la ingeniería institucional que iba adoptando el nuevo Estado. En este sentido, Zegada propuso una instrucción basada en los principios del catolicismo romano y su texto tuvo muy buena recepción por parte de las autoridades eclesiásticas de la Confederación.

Por otro lado, la experiencia de la primera mitad del siglo XIX, determinó que Zegada se definiera a favor del gobierno nacional. El urquicismo en el poder le había mostrado que la tan anhelada organización política y eclesiástica era posible. Otro factor que no puede ser soslayado es la expectativa generada en torno a la promoción a alguna de las sillas episcopales de la Confederación.

Los contenidos que analizamos de las Reflexiones religiosas y sociales que se incorporaron en la reedición del catecismo, fueron acordados con el ministro Gutiérrez y refirieron especialmente a los ramos de religión, educación e institucionalización del poder. Para destacar la acción del gobierno de Urquiza, usó de la crítica a las prácticas políticas del rosismo distanciándolas de las emprendidas por el gobierno nacional urquicista. En su interpretación utilizó la Historia de la Salvación, la Biblia, asimilando el gobierno de Rosas con la tiranía y al 
despotismo que el Pueblo elegido de Dios sufrió en manos del faraón egipcio, mientras que su liberación la asoció al accionar del poder central en el nuevo orden liderado por Justo José de Urquiza. En este punto, construyó su heroicidad significándola de forma explícita al líder de los israelitas, Moisés. La Alianza sellada entre Dios y su Pueblo implicaba el establecimiento del culto religioso, así la victoria y el gobierno de Urquiza -al haber sido propiciado por la Divina Providencia- implicaba también cimentar la religión católica en el horizonte republicano que se abría. Convocaba por ello, a los fieles-ciudadanos a apoyar las medidas del gobierno, pues el programa de gestión era un programa evangélico. Así, en clave religiosa exaltaba la marcha administrativa del héroe y legitimaba el nuevo orden político iniciado en 1853.

En fin, la historia de la segunda edición del catecismo sugiere que el nuevo orden estatal moderno que surgía de la mano de los dirigentes de la Confederación urquicista en 1853, utilizó los dispositivos y los modelos del catolicismo romano para proporcionar mayor cohesión a su gobierno. En el catecismo se llamó a adoptar la Constitución Nacional y se elogió las medidas gubernamentales, lo que muestra la ineludible reafirmación del Estado en ciernes. A su vez, el catolicismo romano contaba con un instrumento financiado por el gobierno, para propagar también su doctrina en un contexto de reorganización y centralización eclesiástica. De allí que sea posible conjeturar la mutua retroalimentación entre poder temporal y poder celestial en la Argentina hacia mediados del siglo XIX.

\section{ARCHIVOS}

$\begin{array}{llll}\text { AMHN } & \text { Archivo del Museo Histórico del Norte } & \text { Salta, Argentina } \\ \text { BNRA } & \begin{array}{l}\text { Biblioteca Nacional de la República } \\ \text { Buenos Aires, } \\ \text { Argentina }\end{array} & \begin{array}{l}\text { Argentina } \\ \text { ACCSFS }\end{array} & \begin{array}{l}\text { Archivo del Complejo Cultural San } \\ \text { Francisco de Salta }\end{array}\end{array}$

\section{FUENTES EDITADAS}

Zegada, Escolástico; Instrucciones Cristianas, primera edición, Imprenta Beche y Cia, Sucre, 1847.

Zegada, Escolástico; Instrucciones Cristianas, segunda edición, Imprenta del Uruguay, Entre Ríos, 1857.

Zegada, Escolástico; Instrucciones Cristianas, tercera edición, Imprenta Pablo Coni, Buenos Aires, 1869. 
Archivo epistolario del Doctor Juan María Gutiérrez, tomo III, Biblioteca del Congreso de la Nación. Buenos Aires, 1982.

\section{BIBLIOGRAFÍA}

Ayrolo, V. 2009. "La travesía de la "Iglesia" del Río de la Plata, Tucumán y Cuyo entre la Colonia y la Nación": 25-52, en: A Agreja Católica Em Mato Grosso E Os Cem Anos Da Arquidiocese De Cuiabá (1910-2010). Cuiaba-Brasil: Ed. UFMT Editora de la Universidad Federal de Mato Grosso.

Abalo, E. 2009 a. "La Iglesia católica en la época de la Confederación Argentina. El censo eclesiástico de 1854", Tesis de Licenciatura en Historia. Universidad Nacional de Tucumán.

Abalo, E. 2009 b. “"Nada tiene el Clero, nada la Iglesia de que subsistir" Las rentas eclesiásticas en la Época de la Confederación Argentina": 91-117. En: Res Gesta 47, Rosario: UCA.

Abalo, E. 2012. "Construir la Iglesia: clero, feligresía y Estado provincial ante la edificación de templos en ña vicaría foránea de Tucumán (1852-1897)": 5-26, en: Bicentenario. Revista de Historia de Chile y América, Vol. 11, Nro. 2. Santiago de Chile.

Arredondo López, M. A. 2004. "Desplazando al rey en la escuela de la nueva nación mexicana: El "Catecismo de la República"”, Historia de la Educación. Núm. 22-24: 259-272. Ediciones Universidad de Salamanca.

Auza, N. T. 1979. "La política religiosa de la Confederación. El censo religioso de 1854", en Revista Histórica, 3. Buenos Aires.

Auza, N. T. 1982. "Los seminarios y la formación de eclesiásticos en el período de la confederación 1852-1861", Teología. T. XIX. Núm. 39: 63-83. Universidad Católica Argentina.

Bragoni, B. y Míguez, E. 2010. "Introducción: de la periferia al centro: la formación de un sistema político nacional, 1852-1880", en B. Bragoni y E. Míguez (coords.) Un nuevo orden político. Provincias y Estado Nacional 1852-1880. 9-28. Buenos Aires. Biblios.

Bosch, B. 1980. Urquiza y su tiempo, Buenos Aires: Editorial universitaria de Buenos Aires. 
CONSTRUYENDO CONSENSO Y LEGITIMIDAD. LA PROYECCIÓN 399

POLÍTICA DEL CATECISMO DE ESCOLÁSTICO ZEGADA EN TIEMPOS

DE LA CONFEDERACIÓN ARGENTINA (1853-1862)

Cañizares Esguerra, J. 2013. "Son las Mujeres las que Defienden al Rey con Espadas y son los Liberales los que Queman Herejes: EI Antiguo Testamento y las Revoluciones de Independencia en la Monarquía de España", en: 20/10, El Mundo Atlántico e Iberoamérica, 1750-1850, Nro. 2, México. En línea: http://www.2010historia.com/emaylmi-v2-articulo1.phtml (consulta el 11 de mayo de 2014).

Chartier, R. 1993. "Manuales de civilidad. Distinción y divulgación: la civilidad y sus libros", en Libros, lecturas y lectores en la Edad Moderna: 246-283. Madrid: Alianza.

Connaughton, B. 1995. "La sacralización de lo cívico: la imagen religiosa en el discurso cívico-patriótico del México independiente. Puebla (1827-1853)": en: Matute, Á., Trejo, E. y Connaughton, B. (coords.) Estado, iglesia y sociedad en México. Siglo XIX: 223-250México: UNAM.

Di Stefano, R. 2003. "Lecturas políticas de la Biblia en la revolución rioplatense (1810-1833)", Anuario de la Iglesia. Núm. XII: 201-224. Universidad de Navarra.

Donoso, R. 1943. "Estudio preliminar", en Revista de Historia y Geografía Chilena: 12-119. México.

Elias, N. 2009 [1986]. Proceso de la civilización, México: FCE.,

Goldman, N. 2005 (dir.). Nueva Historia Argentina. Revolución, República, Confederación (1806-1852). Tomo III. Buenos Aires: Sudamericana.

Lanteri, A. L. 2008. "La justicia federal en la 'Confederación' Argentina (1854-1861). Apuntes sobre un intento de articulación entre Nación y provincias", Revistas Territórios e Fronteiras, Vol. 1. Núm. 1: 3561. Mestrado em História do ICHS/UFMT.

Lanteri, A. L. 2010. "La conformación de una dirigencia nacional. Notas sobre la dinámica política en el Congreso de Paraná (1854-1861)", en V. Ayrolo (comp.) Economía, Sociedad y Política en el Río de la Plata del Siglo XIX. Problemas y debates: 125-139. Rosario: Prohistoria.

Lanteri, A. L. 2013. "La 'Confederación' desde sus actores. La conformación de una dirigencia nacional en un nuevo orden político (1852-1862)", en Lanteri, A. L. Actores e identidades en la construcción del Estado nacional: 129-170. Buenos Aires: Teseo 
Lemaitre, N. 2002 (dir.). Histoire des curés, París: Fayard.

Lida, M. 2006 a. "Una Iglesia a la medida del Estado: la formación de la Iglesia nacional en la Argentina (1853-1865)", Prohistoria. Año X. Núm. 10: 27-46. Rosario.

Lida, M. 2006 b. "Prensa católica sociedad en la construcción de la Iglesia argentina en la segunda mitad del siglo XIX": 51-75, en: Anuario de Estudios Americanos, 63, 1, enero-junio.

Lida, M. 2007. "El presupuesto de culto en la Argentina y sus debates. Estado y saciedad ante el proceso de construcción de la Iglesia (1853-1880)", Revista Andes. Antropología e Historia, Núm. 17: 49-76. CEPIHA-UNSa.

Martínez, I. 2010. "Coincidencias sin acuerdo. Los primeros contactos entre el gobierno argentino y la Santa Sede en el proceso de construcción de la Iglesia nacional (1851-1860)", Nuevo Mundo Mundos Nuevos, Debates, puesto en línea el 11 de marzo de 2010: http://nuevomundo.revues.org/59082.

Martínez, I. 2013. Una Nación para la Iglesia argentina. Construcción del Estado y jurisdicciones eclesiásticas en el siglo XIX. Buenos Aires: Academia Nacional de la Historia.

Medina, F. 2012. "Entre la llustración española y las ideas contrarrevolucionarias francesas: el universo intelectual de la producción escrita de Escolástico Zegada (1813-1871)", en G. Caretta e I. Zacca (comps.) Derroteros en la construcción de Religiosidades. Sujetos, instituciones y poder en Sudamérica, siglos XVII al XX: 107-122. CEPIHA, UNSTA, CONICET.

Paz, G. 2003. "El gobierno de los "conspicuos": familia y poder en Jujuy, 1853-1875", en H. Sabato y A. Lettieri (comps.) La vida política en la Argentina del siglo XIX. Armas, votos y voces: 223-241. Buenos Aires: FCE.

Peire, J. 2000. El taller de los espejos. Iglesia e imaginario 17671815. Buenos Aires: Editorial Claridad.

Romero, J. L. 2008. "El pensamiento conciliador y la organización nacional", en Las ideas Políticas en la Argentina: 133-169. Buenos Aires: FCE. 
CONSTRUYENDO CONSENSO Y LEGITIMIDAD. LA PROYECCIÓN 401

POLÍTICA DEL CATECISMO DE ESCOLÁSTICO ZEGADA EN TIEMPOS

DE LA CONFEDERACIÓN ARGENTINA (1853-1862)

Robles, A.; Cappello, H. y López Sánchez, J. 2007. "Características del proyecto educativo bolivariano: el tránsito del vasallo al ciudadano (1810-1830)", Revista Internacional de Ciencias Sociales y Humanidades. Año/vol. XVII. Núm. 001: 93-113. Universidad Autónoma de Tamaulipas.

Rosanvallon, P. 2002. Por una historia conceptual de lo político. Buenos Aires: FCE.

Sábato, H. 2012. Historia de la Argentina, 1852-1890. Buenos Aires: Siglo XXI.

Sánchez de Bustamante, T. 1957. Biografías históricas de Jujuy. Universidad Nacional de Tucumán.

Salcedo Baeza, R. 1996. "Actores políticos en los catecismos patriotas y republicanos americanos, 1810-1827", Historia Mexicana. XLV. Nro. 3: 501-538. México.

Sotés Elizalde, M. Á. 2009. "Catecismos políticos e instrucción política y moral de los ciudadanos (siglos XVIII y XIX) en Francia y España", Educación XXI. Núm. 12: 201-218. España: Universidad Nacional de Educación a Distancia.

Terán, J. Sin año. "Don Juan María Gutiérrez", en Gutiérrez, Juan María; Críticas y Narraciones: XV-XXIV. Buenos Aires: Editorial Jackson.

Ternavasio, M. 2009. Historia de la Argentina, 1806-1852. Buenos Aires: Siglo XXI.

Traffano, D. 2007. "Educación, civismo y catecismos políticos. Oaxaca, segunda mitad del siglo XIX", Revista Mexicana de Investigación Educativa. Vol. 12. Núm. 12: 1043-1063.

Vergara, M. Á. 1940. Zegada. Sacerdote y Patricio de Jujuy. Jujuy: Edición especial del Gobierno de Jujuy. 